\title{
Influence Of Rank Of Surgeon On The Outcome Of Cataract Surgery In Plateau State Nigeria.
}

\author{
Authors: \\ ${ }^{1}$ Ojo Perpetua ODUGBO; FWACS, FMCOphth \\ 'Olufemi Emmanuel BABALOLA; FWACS, FMCOphth \\ ${ }^{3}$ Regina Enubi MORGAN; FWACS, FMCOphth
}

${ }^{I}$ Corresponding author

Department of Ophthalmology, Faculty of Medical Sciences, University of Jos, P.M.B. 2084, Jos-

Nigeria. E-mail: odugp@yahoo.com Telephone: 234-8052717996

${ }^{2}$ Rachel Eye Centre, Onitsha Crescent, Garki 2, Abuja- Nigeria

${ }^{3}$ Department of Ophthalmology, National Hospital, Abuja-Nigeria

Key Words: Cataract, blindness, outcome, rank of surgeon

Total number of pages: 16 Word Count: 2573

\begin{abstract}
Aim: To evaluate the outcome of cataract surgery in terms of restoration of visual function in the operated eye in relation to the rank and experience of surgeons.

Methodology: Four centres were selected using stratified random sampling technique. Consecutive patients, who had cataract extraction from $1^{\text {st }}$ October $2002-31^{\text {st }}$ March 2003, were recruited. The study instrument was a pre-tested structured questionnaire. Preoperative visual acuity (VA), type of cataract, type of surgery, official rank of surgeon, peri-operative events, postoperative events and physiological outcome were documented.
\end{abstract}

Result: 200 patients were recruited. Mean age was 61.08 years. 219 eyes were operated. 101(46.1\%) were operated by consultants, 51(23.3\%) by resident doctors and 67(30.6\%) by diplomats. Intraoperative complications were encountered in 57 (26\%) eyes. Of these 15(26.3\%), 16(28.1\%), $26(45.6 \%)$ eyes were operated by consultants, resident doctors and diplomats respectively. Of 161 eyes reassessed six weeks after surgery, 86(53.4\%) had good outcome $(V A=6 / 18)$, while 18(11.2\%) had poor outcome $(V A<6 / 60)$ with available correction. 56(68.3\%), 18(42.9\%), and $12(32.4 \%)$ eyes operated by consultants, residents, and diplomats had a good outcome with available correction respectively $(p<0.001)$. Of 125 eyes refracted six weeks after surgery, 92(73.6\%) had good outcome while 11(8.8\%) had poor outcome with best correction. 65(89.1\%), 16(57.1\%), and 11(45.8\%) eyes operated by consultants, residents and diplomats had a good outcome with best correction respectively

$(p<0.001)$.

Conclusion: Resident doctors and diplomates encountered most of the intraoperative complications and recorded a poorer outcome. This calls for closer supervision of resident doctors and diplomates while in training.

\section{Introduction}

Blindness is one of the most disabling impairments to beset human beings due to its wide socioeconomic implications. Cataract, an avoidable cause of blindness (best-corrected visual acuity $<{ }_{60}^{3}$ in the better eye), is the leading cause of blindness and low vision worldwide. It accounts for 17.7 million of the 37 million blind persons globally ${ }^{1}$ Ageing is the commonest cause of cataract. Exponential growth of the world population and life expectancy, results in an

increase in the elderly population resulting in a greater number of people with visual loss and blindness from cataract needing surgery ${ }^{2}$. An estimated 9 million blind persons live in Africa, about $50 \%$ due to cataract ${ }^{1}$ The prevalence of blinding bilateral cataract in Africa is estimated to be $0.5 \%{ }^{4}$. With a population of 140 million and blindness prevalence rate of $0.74 \%{ }^{5}$, there are at least 1.04 million blind people in Nigeria. Cataract therefore accounts for at least 520,000 blind people 
with another 1.041 .6 million visually impaired by it. Surgical extraction and correction of the resultant aphakia is the only available modality of treatment ${ }^{7}$. Cataract surgery is one of the most important surgical procedures learned by ophthalmology residents during training ${ }^{8}$. Intraocular microsurgery has a narrow tolerance for intraoperative errors and even small missteps in surgical judgment or technique may result in irreversible adverse surgical outcome'. The development of expertise in surgical technique must parallel the acquisition of knowledge and correct professional attitudes during residency training ${ }^{10}$. Cataract outcome is the result of surgical intervention for visual impairment or blindness due to cataract $^{11}$. According to $\mathrm{WHO}$ guideline, a postoperative visual acuity of $=6 / 18$ is good outcome, $<6 / 18-6 / 60$ is borderline outcome while $<6 / 60$ is a poor outcome ${ }^{12}$.

In order to promote uptake of cataract surgery, it is essential that the outcome surgery is made increasingly better. This study was designed to serve as an indicator of areas of performance that require improvement through continued professional development as it will serve as the key to improving the quantity and quality of cataract surgery in the study area.

\section{Objective}

To evaluate the outcome of cataract surgery in terms of restoration of visual function in the operated eye, objectively measured by visual acuity (VA) in relation to the rank and experience of surgeons.

\section{Materials and Methods}

This was an observational, multi-center, prospective study in which patients with agerelated cataract who had cataract extraction in Plateau state within a six month period $\left(1^{\text {st }}-\right.$ October $200231^{\text {st }}$ March 2003) constituted the target population.

Approval for the conduct of the study was obtained from the Medical Ethics Committee of Jos University Teaching Hospital. An informed consent was obtained from the Medical Directors of all the selected study sites and all recruited patients.

Stratified random sampling technique was used. All centers in Plateau state where cataract surgical services are rendered were listed. These were subdivided into the following four groups to constitute the sampling frame. Tertiary Health Center(1),
State Government Owned Secondary Health Center(2), Missionary Owned Secondary Health Center(3), Private Hospitals(4). One center was selected from each of the above four groups by balloting. One center was selected from each of the four groups.

Based on a prevalence rate of cataract blindness of $0.5 \%{ }^{4}$, estimated Plateau state population of 2.78 million, with about $15.3 \%$ of the population aged 40 years or more ${ }^{13}$ a precision of $\pm 10 \%$ and a $95 \%$ confidence limit, a minimum sample size of 192 patients was calculated. This figure was approximated to 200. The number of patients was selected from each of the centers based on the voume of cataract surgery in each center.

Inclusion Criteria: A "Case" implied a patient aged forty years or more with age related cataract, who had no co-existing ocular morbidity likely to influence outcome, and who had cataract surgery in a selected study site from $1^{\text {st }}$ October $200231^{\text {st }}$ March 2003.

Consecutive cases (case series) were recruited. The study instrument was a pre-tested structured questionnaire. Research assistants were trained and inter-observer error assessed, corrected and standardized.

Protocol: Demographic data was obtained. Preoperative visual acuity (VA) was measured uniocularly and binocularly with the snellen chart. Information on the rank of surgeon by official status (consultants, senior registrar, registrar, and diplomats in ophthalmology), type of anaesthesia and surgery, type of intraocular lens (IOL) implanted and intraoperative complications were obtained from the operation notes. Patients were re-examined on the first postoperative day and 6weeks after surgery. At this period, VA was reassessed; the operated eye was examined with a pen-torch, ophthalmoscope and a slit-lamp biomicroscope. Refraction was done with a streak retinoscope, trial lens frame, trial lenses and snellen's chart six weeks after surgery. The presenting VA and best-corrected VA were criteria used for classifying the physiological (visual) outcome as good $(=6 / 18)$, borderline $(<6 / 60-3 / 60)$ or poor $(<3 / 60)$.

Epi-info Version 6 software was used for analysis.

\section{Results}

Two hundred patients were recruited for the study, $119(59.5 \%)$ males and $81(40.5 \%)$ females. The age ranged from 42-86 years (mean: 61.08 years, 
SD: 9.4). $175(87.5 \%)$ were aged 50 years or more. Sixty-nine persons $(34.5 \%)$ were farmers. Ninetyseven $(48.5 \%)$ patients had binocular cataract blindness while $67(33.5 \%)$ patients had uniocular blindness pre-operatively. 219 eyes were operated. Of these, $156(71.2 \%)$ had mature cataract, 28 $(12.8 \%)$ had Morgagnian cataract, 24 (10.9\%) had hyper-matured cataract, $7(3.2 \%)$ had posterior subcapsular cataract, $3(1.4 \%)$ had nuclear cataract while $1(0.5 \%)$ had cortical cataract.

All surgeries were performed under local anaesthesia. Fifteen surgeons performed the surgeries; $7(46.7 \%)$ consultants, $5(33.3 \%)$ resident doctors, and 3(20\%) diplomates.

One hundred and one eyes $(46.1 \%)$ were operated by consultants, 51 eyes $(23.3 \%)$ by resident doctors and 67 eyes $(30.6 \%)$ by diplomats (table 1$)$.

One hundred and sixty-nine eyes (77.2\%) had extracapsular cataract extraction and posterior chamber intraocular lens implantation (ECCE+PCIOL) by the conventional large incision method. Three eyes (1.4\%) had ECCE and PCIOL implantation through the manual stitch-less small incision cataract surgery (SICS) method. 21(9.6\%) eyes had ECCE with anterior chamber intraocular lens implantation (ACIOL), one $(0.5 \%)$ eye had intracapsular cataract extraction (ICCE) with ACIOL implantation. On the whole 194 eyes $(88.6 \%)$ had IOL implantation (table 1).

Of the 169 eyes that had conventional ECCE + PCIOL, 91 eyes $(53.8 \%)$ were operated on by consultants. 3 eyes had stitchless cataract surgery and were operated on by a consultant. Of 21 eyes that had ECCE and ACIOL implantation, $16(76.2 \%)$ were operated on by a diplomate.

Intraoperative complications were encountered in 57 (26\%) eyes (table2). 15(26.3\%) were operated by consultants, $16(28.1 \%)$ by resident doctors and $26(45.6 \%)$ by diplomates. The complication rates were 2 eyes/consultant, 3eyes/resident doctor and 9 eyes/ diplomate. This was statistically significant $(p<0.05)$. The most frequently encountered intraoperative complication were posterior capsule rupture (PCR) in $32(14.6 \%)$ eyes, retained soft lens matter (SLM) in $22(10.0 \%)$ eyes and vitreous loss (VL) in $18(8.2 \%)$ eyes.

Figure 1 shows the physiological outcome on the first post-operative day, 23 eyes $(10.5 \%)$ had good outcome, $102(46.6 \%)$ eyes had borderline outcome while $94(42.9 \%)$ eyes had a poor outcome. Of the 101 eyes operated by consultants, $17(16.7 \%)$ had good outcome, $71(70.3 \%)$ had borderline outcome while 13 eyes (13\%) had poor outcome on the first post-operative day. Of the 51 eyes operated on by resident doctors, $4(7.8 \%)$ had good outcome, $13(25.5 \%)$ had borderline outcome while $34(66.7 \%)$ had a poor outcome on the first post-operative day. Of the 67 eyes operated on by diplomats, $2(2.9 \%)$ had a good outcome, $18(26.9 \%)$ had a borderline outcome while $47(70.2 \%)$ had a poor outcome at the same period. Outcome on the first postoperative day was better in eyes operated on by consultants $(\mathrm{p}<0.001)$.

The main early postoperative complications were mild-moderate anterior uveitis in $178(81.2 \%)$ eyes, striate keratopathy in $119(54.3 \%)$ eyes and corneal epithelial oedema in $52(23.7 \%)$ eyes 161 eyes of 151 patients were re-assessed six weeks after surgery. Of these, $82(50.9 \%), 42(26.1 \%)$ and $37(23 \%)$ were operated on by consultants, residents and diplomats respectively. 86 eyes $(53.4 \%)$ had good outcome, $57(35.4 \%)$ eyes had borderline outcome while 18 eyes $(11.2 \%)$ had poor outcome with available correction (figure 2 ).

Of the 82 eyes operated by consultants, $56(68.3 \%)$ eyes had a good outcome, 24(29.3\%) had a borderline outcome while $2(2.4 \%)$ eyes had a poor outcome with available correction, which also implies the presenting vision (figure 2).

Of the 42 eyes operated on by residents, $18(42.9 \%)$ had a good outcome while $9(21.4 \%)$ had a poor outcome. Of the 37 eyes operated by diplomats, $12(32.4 \%)$ had a good outcome, while 7 had a poor outcome (figure 2). The physiological outcome with available correction is better with the rank of the surgeon $(\mathrm{p}<0.001)$.

125 eyes were refracted six weeks after surgery. Of these, 92(73.6\%) had good outcome, 22(17.6\%) had borderline outcome while $11(8.8 \%)$ had a poor outcome (figure 3 ).

Of these 125 eyes, $73(58.4 \%)$ eyes were operated on by consultants, $28(22.4 \%)$ eyes were operated on by resident doctors while $24(19.2 \%)$ were operated on by diplomats. Of the 73 eyes operated on by consultants, 65(89.1\%) eyes had a good outcome, $6(8.2 \%)$ eyes had borderline outcome while $2(2.7 \%)$ eyes had a poor outcome. Of the 28 eyes operated on by resident doctors, 16(57.1\%) had a good outcome, 7(25) had a borderline outcome while $5(17.9 \%)$ had a poor outcome. Of the 24 eyes operated on by diplomates, 11(45.8\%) eyes had a good outcome, $9(37.5 \%)$ had a borderline outcome while $4(16.7 \%)$ had a poor outcome (figure 3$)$. This was statistically significant $(\mathrm{p}<0.001)$. 
Table 1: Distribution of Type of Cataract Surgery

Performed by Rank of Surgeon

\begin{tabular}{|c|c|c|c|c|c|c|c|}
\hline \multirow{2}{*}{$\begin{array}{l}\text { Rank Of } \\
\text { Surgeon }\end{array}$} & \multicolumn{6}{|c|}{ Type Of Cataract Surgery } & \multirow{2}{*}{ Total } \\
\hline & ECCE + & Stitches & ECCE + & ICCE & ECCE & ICCE & \\
\hline & PCIOL & ECCE & ACIOL & ACIOL & & & \\
\hline & No (\%) & No (\%) & No (\%) & No (\%) & No (\%) & No (\%) & No (\%) \\
\hline Consultants & $91(53.8)$ & $3(100)$ & $3(14.3)$ & $0(0)$ & $4(40)$ & $0(0)$ & $101(46.1)$ \\
\hline $\begin{array}{l}\text { Resident } \\
\text { doctors }\end{array}$ & $44(26.1)$ & $0(0)$ & $2(9.5)$ & $0(0)$ & $5(50)$ & $0(0)$ & $51(23.3)$ \\
\hline Diplomates & $34(20.1)$ & $0(0)$ & $16(76.2)$ & $1(100)$ & (0) & $15(100)$ & $67(30.6)$ \\
\hline Total & $169(100)$ & $3(100)$ & $21(100)$ & $1(100)$ & $10(100)$ & $15(100)$ & $219(100)$ \\
\hline
\end{tabular}

Table 2: Frequency of Intra-Operative Complications by Rank of Surgeon

\begin{tabular}{lllll}
\hline & \multicolumn{3}{c}{ Rank of Surgeon } & Total \\
\hline & Consultants & Resident & Diplomats & \\
\hline Intra-operative Events & No (\%) & No (\%) & No (\%) & No (\%) \\
\hline $\begin{array}{l}\text { No intra-operative } \\
\text { complication }\end{array}$ & $86(85.1)$ & $35(68.6)$ & $41(61.2)$ & $162(74)$ \\
$\begin{array}{l}\text { Intra-operative } \\
\text { complication(s) encountered }\end{array}$ & $15(14.9)$ & $16(31.4)$ & $26(38.8)$ & $57(26)$ \\
Total & $\mathbf{1 0 1 ( 1 0 0 )}$ & $\mathbf{5 1 ( 1 0 0 )}$ & $\mathbf{6 7}(\mathbf{1 0 0 )}$ & $\mathbf{2 1 9 ( 1 0 0 )}$ \\
\hline
\end{tabular}
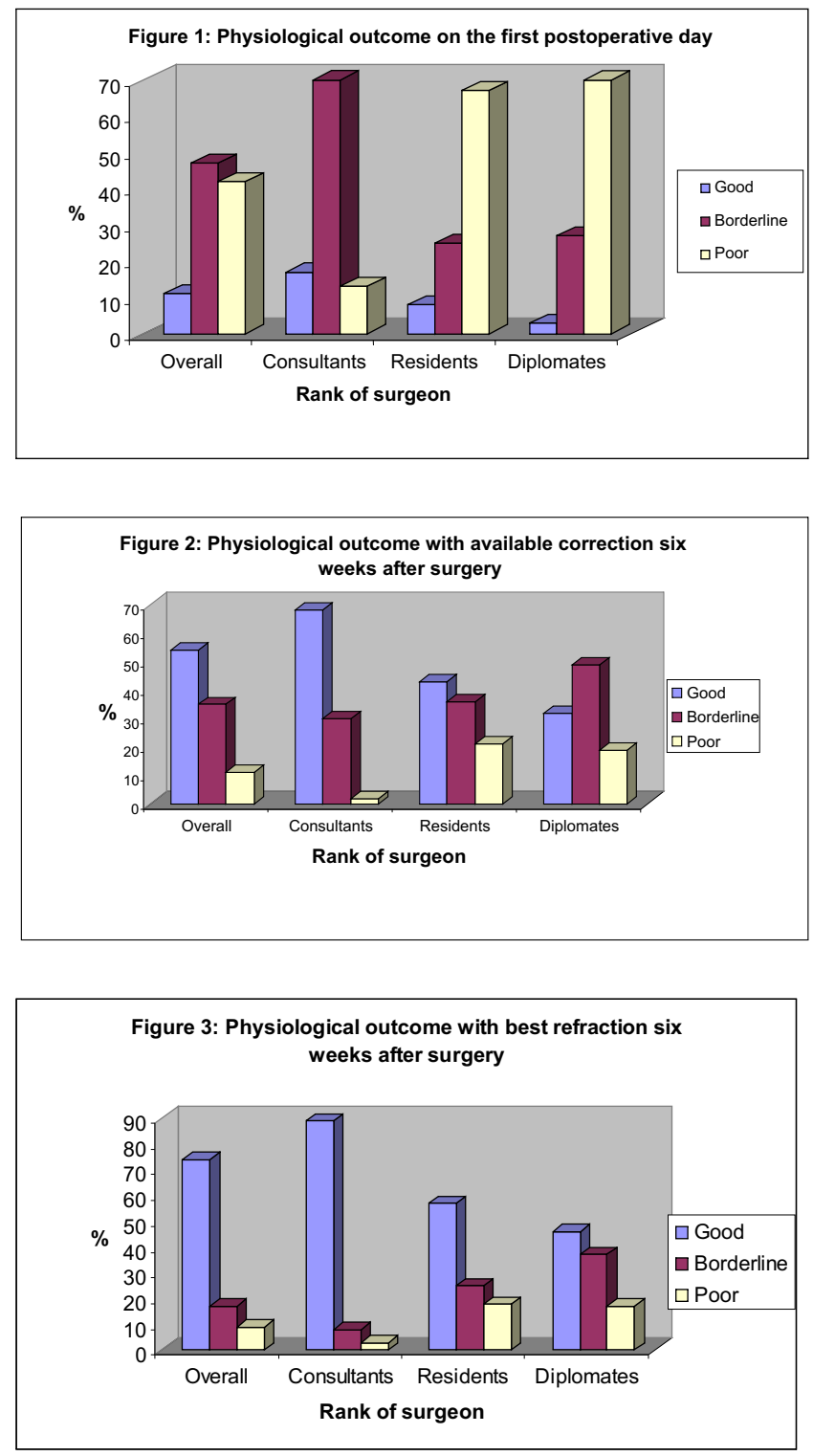

\section{Discussions}

Outcome studies should not be seen as a witch-hunt of surgeons neither should they be used to compare surgeons or centers, since case selection, surgical skills, procedures, facilities, follow-up periods and other factors affecting outcome, differ by surgeons and by centers over time. It is however, useful to evaluate the surgical learning curve of resident doctors during their training. In all, 194(88.6\%) had IOL implantation and of the 51 eyes operated on by resident doctors, $44(86.3 \%)$ had $\mathrm{PCIOL}$ implantation. This is close to a PCIOL implantation rate of $98.8 \%$ among resident doctors observed by Cruz et $\mathrm{al}^{14}$. Though, not a direct indicator of the quality of visual outcome, the proportion of patients in whom an IOL was implanted can sometimes be used as an indicator of the trend towards better visual rehabilitation in cataract surgery ${ }^{15}$. The higher frequency of occurrence of intraoperative complication observed with diplomates could be due to the fact that diplomats have a shorter duration of training (18 months) while resident doctors have a longer duration of training (6years). Diplomates work independently in secondary health care centers and thus operate without the supervision of consultants, while resident doctors work and carry out operative procedures in tertiary health care centers under the supervision of consultants. Sixteen $(76.2 \%)$ of the 21 eyes that had ECCE and ACIOL implantation were operated on by a diplomate, (table 1 ). The only diplomate who could insert PCIOL was less than 5years post qualification. Posterior capsule rupture (PCR) was the major cause of failed PCIOL implantation especially, if associated with vitreous disturbances. A vitreous loss rate of $8.2 \%$ observed is higher than what was observed by Blanquists et $\mathrm{al}^{16}$, Cruz et $\mathrm{al}^{14}$ and Quillen et $\mathrm{al}^{8}$ who observed a vitreous loss rate of $4.5 \%, 5.5 \%$ and $4.8 \%$ respectively. It is however better than what was observed by Thomas et $\mathrm{al}^{17}$ and Smith et $\mathrm{al}^{18}$ who observed a vitreous loss rate of $10 \%$ and $16 \%$ respectively.

Intraoperative complications were encountered in $57(26 \%)$ eyes. This is worse than the findings of Mahmoud et $\mathrm{al}^{19}$, Bekibele ${ }^{20}$ and Yorton et $\mathrm{al}^{21}$ who observed that $10.2 \%, 13.1 \%$ and $9.9 \%$ of cases had intraoperative complications respectively. Surgical experience had a significant effect on the number of errors observed in this study; similar to what was observed by Gauba et $\mathrm{al}^{22}$.

The visual acuity had generally improved on the first postoperative day. Twenty-three eyes $(10.5 \%)$ had a good outcome. This result may have been better if pre-operative ocular biometry was done to determine the appropriate intraocular lens power. The higher the rank of surgeon, the better the visual outcome on the first postoperative day. Events on this day may be an indicator of the extent of 
intraoperative manipulation and could be predictive of the final outcome in an eye.

Consultants also had significantly better outcome (68.3\% and $89.1 \%$ record of good outcome with available and best correction respectively) compared to resident doctors and diplomats, similar to what was observed by Golgate et al in India $^{23}$. This is a strong indicator that the WHO recommended values is attainable in our environment.

This observed difference could narrow down with time as cataract outcome tend to improve with time (this observation was made just six weeks after surgery). Straatsma et al however, had a contrary view. They reported there was no statistically significant difference between cataract outcomes in eyes operated by resident doctors and experienced ophthalmic surgeon ${ }^{24}$. This may reflect differences in quality of training.

The proportion of patients operated by resident doctors who had a good outcome after best correction $(57.1 \%)$ ) in this study is worse than what was observed by Cruz et al ${ }^{14}$, Smith et al ${ }^{18}$ and Straatsma et $\mathrm{al}^{24}$ who observed a good outcome in $92.6 \%, 84 \%$ and $88 \%$ of eyes respectively. The major determinant of good cataract outcome (and outcome of any ocular surgery) is the surgeon's skill, for which adequate training is mandatory.

Errors in an early stage of the procedure can lead to downstream complications or difficulty with other parts of the procedure. Teaching and assessing resident doctors and diploma student's surgical performance in ophthalmology pose special problems with unique ethical, technical and practical problems.

First, the performance of a technique that has not been mastered by the resident surgeon in live patients produces unique ethical issues in terms of disclosure, informed consent and faculty supervision. In addition, the number of cases available for residents is increasingly under threat. The Iowa ophthalmology wet laboratory curriculum for teaching and assessing cataract surgical competency form the basis for successfully utilizing the wet laboratory to teach and assess aspects of resident surgical competence in cataract surgery ${ }^{9}$. More time can be dedicated to mastering the various steps of cataract extraction in the wet lab.

The format of surgical skill assessment has undergone changes in recent years, with a shifting trend from the apprenticeship model to standardized objective methods of assessment. Training schemes in which a senior supervising surgeon assesses the technical proficiency and progress of trainees have been shown to be subjective, with significant inter-observer variability even among experts in the field. Objective methods of surgical performance evaluation and monitoring have been deemed essential to consistently identify and correct technical errors ${ }^{22}$.

Various tools have being devised to objectively assess resident's surgical skills and intra-operative events. They include Eye Surgical Skills Assessment Test (ESSAT) ${ }^{25}$, Human reliability analysis of cataract surgery tool ${ }^{22}$, Objective Assessment of Skills in Intraocular Surgery $(\mathrm{OASIS})^{26}$, and the Global Rating Assessment of Skills in Intraocular Surgery (GRASIS) ${ }^{27}$. They can also be used to assess a resident's surgical care of patients as well as resident's surgical knowledge, preparedness and interpersonal skill.

In conclusion, resident doctors and diplomates should be closely supervised and adequately assessed during their training in order to reduce the risk of intraoperative complications, improve their surgical skills and improve cataract outcome as satisfied cataract operated patients serve as excellent motivators for others to have surgery thereby increasing uptake of cataract services in the country.

\section{Acknowledgment:}

We are grateful to the Chief Medical Directors of Jos University Teaching Hospital, Plateau State Specialist Hospital, COCIN Hospital Mangu, NaAllah Na-Kowa Hospital and all resident doctors of Department of Ophthalmology, Jos University Teaching Hospital.

\section{References:}

1. Resnikoff S, Pascolini D, Etya'ale D, Kocur I, Pararajasegaram R, Pokharel GP, Mariotti SP. Global data on visual impairment in $\mathrm{t}$ the year 2002. Bull. WHO 2004;82:844-851

2. Foster A. Vision 2020: The Cataract Challenge. J. Comm. Eye Health 2000; 13(34):17-19.

3. Apple DJ, Ram J, Foster A, Peng Q. Blindness in the World. Elimination of cataract blindness: A Global Perspective. Special Supplement. Surv. Ophthalmol. 2000; 45(1):21-31.

4. Lewallen S, Courtright P. Blindness in Africa: Present situation and future needs. Br. J. Ophthalmol. 2001:85:897-903. 
5. Abdull MM, Sivasubramaniam S, Murthy GV, Gilbert C, Abubakar T, Ezelum C, Rabiu M. Causes of Blindness and Visual Impairment in Nigeria: The Nigeria National Blindness and Visual Impairment Survey. Invest Ophthalmol Vis Sci. 2009 Apr 22. [Epub ahead of print]

6. Osuntokun O. Blindness in Nigeria. The challenge of cataract blindness. Lagos; $4{ }^{\text {th }}$ Faculty of Ophthalmology Lecture. National Postgraduate Medical College of Nigeria; 2001:2-22.

7. Roper-Hall MJ. Stallard's Eye Surgery. $7^{\text {th }}$ Edition, Oxford, CButterworth International. 1980: 282-332.

8. Quillen DA, Phipps SJ. Visual Outcomes and incidence of vitreous loss for residents performing phacoemulsification without prior planned extracapsular cataract extraction experience. Am J Ophthalmol. 2003 May; 135(5):732-3.

9. Lee AG, Greenlee F, Oetting TA, Beaver HA, Johnson AT, Boldt HC, Abramoff M, Olson R, Carter K. The Iowa ophthalmology wet laboratory curriculum for teaching and assessing cataract surgical competency. Ophthalmology. 2007 Jul:114(7) e21-6.

10. Saleh GM, Mitra A, Chung AKK. Objective Structured Assessment of Cataract Surgical Skill. Arch Ophthalmol vol 125, Mar 2007: 363-366.

11. Dandona L, Limburg H. What do we mean by cataract outcomes? J. Comm. Eye Health 2000;13(35):35-36.

12. Limburg H. Monitoring Cataract Surgical Outcomes: Methods and Tools J. Comm. Eye Health 2002; 15(44):51-53.

13. National Population Commission. National and state population projections. Year 2000 diary,Abuja, (C) National Population Commission, 2000:12-15.

14. Cruz OA, Wallace GW, Gay CA, Matoba AY, Koch DD. Visual results and complications of phacoemulsification with intraocular lens implantation performed by ophthalmology residents. Ophthalmology. 1992 Aug; 99(8):1181.

15. Pararajasegaram R. Importance of monitoring cataract surgical outcomes. J. Comm. Eye Health 2002; 15(44):49-50.

16. Blanquists PH, Rugwani RM. Visual outcome after vitreous loss during cataract surgery performed by resident. J cataract Refrac Surg 2002 May;28(5):847-52.

17. Thomas R, Naveen S, Jacob A, Braganza A. Visual outcome and complications of residents learning Phacoemulsification. Indian J Ophthalmol. 1997 Dec; 45(4):215-9.

18. Smith JH, Seiff SR. Outcomes of cataract surgery by residents at a public county hospital. Am J Ophthalmol. 1997 Apr; 123(4): 448-54.

19. Mahmoud BA, Kyari F, Achi IB, Ozomela CP, Abiose A. Audit of Outcome of an Extracapsular Cataract
Extraction and Posterior Chamber Intraocular lens training course. Br. J. Ophthalmol. 2002; 84:848-51.

20. Bekibele CO. Evaluation of the Outcome of ECCE Surgery with PCIOL at Ago-Iwoye, Ogun State, Nigeria. Nigerian Journal of Ophthalmology 2001;1(1):32-36.

21. Yorton D, Foster A. Audit of Extracapsular Cataract Extraction and Posterior Chamber Lens Implantation as a routine treatment for age related cataract in East Africa. Br. J. Ophthalmol 1999;83:897-901.

22. Gauba V, Tsangaris P, Tossounis C, Mitra A, McLean C, Saleh GM. Human Reliability Analysis of Cataract Surgery. Arch Ophthalmol. 2008 Feb;126(2): 173-7.

23. Gogate P, Kulkarni AN. Comparison of Cataract Surgery in a Base Hospital and in Peripheral Eye Camps. J. Comm. Eye Health 2002; 15(42):26-27.

24. Straatsma BR, Meyer KT, Bastek JV, Lightfoot DO. Posterior chamber intraocular lens implantation by ophthalmology residents. A prospective study. Ophthalmology. 1983 Apr; 90(4): 327-35.

25. Fisher JB, Binenbaum G, Tapino $P$, Volpe NJ. Development and face and content validity of an eye surgical skills assessment test for ophthalmology residents. Ophthalmology 2006 Dec:113(12):2364-70.

26. Cremers SL, Ciolino JB, Ferrufino-Ponce ZK , Henderson BA. Objective Assesment Of Skills in Intraocular Surgery (OASIS). Ophthalmology, 2005 Jul: 112(7): 1236-41.

27. Cremers SL, Lora AN, Ferrufino-Ponce ZK. Global Rating Assesment of Skills in Intraocular Surgery (GRASIS). Ophthalmology. 2005 Oct: 112(100:1655-60. 